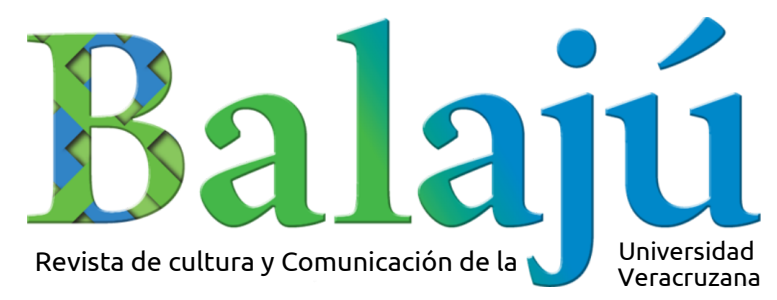

\title{
'Ora sí: ¡Tenemos que ganar! \\ El anarquismo floresmagonista en el cine mexicano
}

\section{Benjamín Marín Meneses}

Universidad Veracruzana

Recibido: 04-04-2020 | Aprobado: 29-11-2020 
'Ora sí: ¡Tenemos que ganar! El anarquismo floresmagonista en el cine mexicano 'Ora sí: ;Tenemos que ganar! Floresmagonist Anarchism in Mexican Cinema

Benjamín Marín Meneses ${ }^{1}$

\title{
Resumen
}

Este artículo analiza la película 'Ora sí: ¡Tenemos que ganar! (Raúl Kamffer, 1978) para rastrear las influencias que tuvo en el filme el pensamiento floresmagonista. Se emplean fuentes historiográficas que se complementan con textos del propio Ricardo Flores Magón, lo que permite encontrar las confluencias y rupturas entre el discurso anarquista textual y el discurso anarquista visual. El estudio revela que existe un pleno conocimiento de las ideas floresmagonistas por parte de los creadores de la película, puesto que hay más similitudes que discordancias.

Palabras clave: Anarquismo, floresmagonismo, rebelión, historiografía, Regeneración.

\begin{abstract}
This article analyzes the film 'Ora sí: ¡Tenenos que ganar! (Raúl Kamffer, 1978) in order to trace the influences of Floresmagonist thought in its production. Using historiographic sources in conjunction with Ricardo Flores Magón's own texts, it highlights confluences and ruptures between the anarchist textual discourse and the anarchist visual discourse, and argues for the influence of Flores Magón's ideas on the creators of the film.
\end{abstract}

Keywords: Anarchism, Floresmagonism, Rebellion, Historiography, Regeneración.

\footnotetext{
${ }^{1}$ Universidad Veracruzana. ORCID: 0000-0002-8131-8082, benja_marin21@outlook.com
} 


\section{'ORA SÍ, ITENEMOS QUE GANAR! \\ EL ANARQUISMO MAGONISTA EN EL CINE MEXICANO}

Benjamín Marín Meneses

\section{Introducción}

En este trabajo no se trata de construir una crítica fílmica; mucho menos se pretende detallar en su totalidad la composición de las secuencias, la pertinencia de los encuadres fílmicos, la calidad de la fotografía, la credibilidad de los efectos visuales, el nivel actoral de los intérpretes o la comunión que la música entabla con las imágenes. Para decirlo más claro, de acuerdo con Ángel Gabilondo, "Leer arte no es cuestión únicamente del reconocimiento de las cualidades estéticas de la cosa, el cual conduciría a afirmaciones sobre su mayor o menor belleza" (Gabilondo en Gadamer, 2006: 17); por lo tanto, lo que se busca es realizar una somera reflexión acerca de los discursos contenidos en 'Ora sí: ¡Tenemos que ganar!, específicamente sobre los que giran en torno a la ideología floresmagonista, eje rector de la trama, que se construye en torno a la filosofía anarquista patentada por Ricardo Flores Magón. Primero, se procederá a presentar la metodología a emplear, al tiempo que discerniremos el papel de la Historia dentro del campo de estudio cinematográfico, con el objetivo de plantear ciertos menesteres requeridos para el estudio del discurso filosófico presente en la película. Después se hará un breve repaso del contexto vivido por la producción audiovisual en la década de los setenta, para dar paso al análisis de las características del ideario ácrata floresmagonista; posteriormente, se presentarán las prédicas y proclamas guionizadas por los creadores de la cinta y finalizaremos con una breve comparación de ambas.

Esta película fue dirigida por Raúl Kamffer, quien la coescribió con Leonor Álvarez. El departamento de cine de la Universidad Nacional Autónoma de México se encargó de la producción. La trama cuenta las andanzas de un grupo de obreros quienes, hartos de los malos tratos recibidos, se organizan para enfrentar al dueño de las minas en las que trabajan. 'Ora sí: ¡Tenemos que ganar! se rodó en 1978, y es protagonizada por Manuel Ojeda, Patricia Reyes Spíndola, Carlos Castañón y Ana Ofelia Murguía. En 1982 ganó el premio Ariel a la mejor película, triunfando también en las categorías de mejor director (Kamffer), mejor edición (Juan Mora Catlett) y mejor fotografía (Toni Kuhn). 


\section{Balajú}

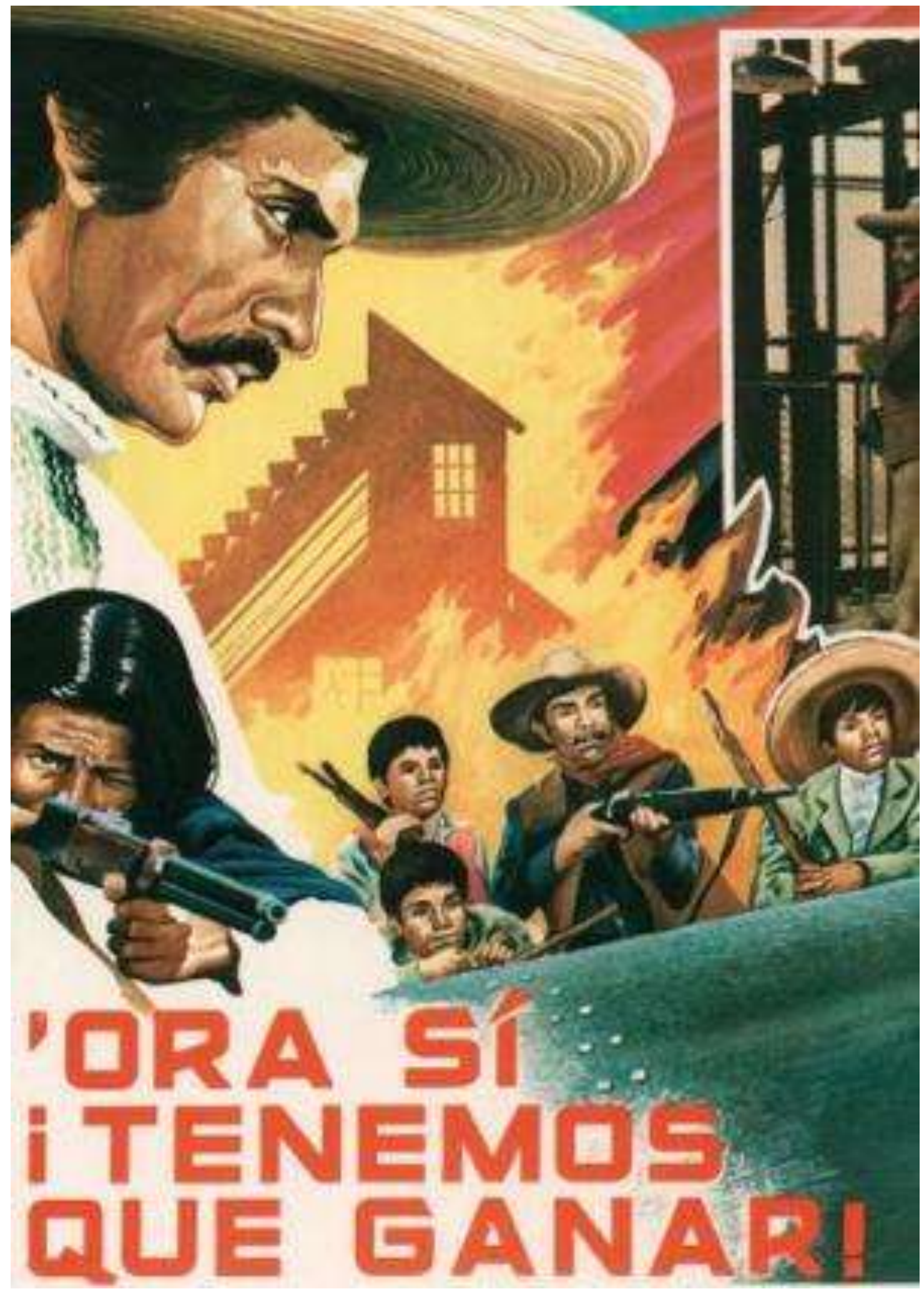

IMAGEN 1. Cartel promocional de la película 'Ora sí: ¡Tenemos que ganar! Obtenida de https://www.filmaffinity.com/es/film858221.html. 


\section{Balajú}

\section{Análisis del discurso cinematográfico en la historia y propuesta metodológica}

El historiador está en constante transformación. Nuevas y diversas metodologías invaden su campo de trabajo, presentándose también nuevas herramientas para explicar los acontecimientos y procesos sociales. Historiar significa reconocer y delimitar continuidades y discontinuidades, comprobar si las cargas ideológicas erigidas en determinada temporalidad y espacialidad son suficientemente fuertes para establecer un paradigma o propiciar su caída. Las corrientes de conocimientos sobre el pasado que llegan a la mesa del historiador se congregan dispersas ante sus ojos, esperando ser acomodadas cual rompecabezas para interpretar la cotidianeidad y vislumbrar probabilidades respecto al futuro.

Asimismo, sus objetos de estudio también fluctúan en variables lapsos de tiempo. Lejos estamos ya de la apetencia exclusiva y excluyente por el archivo; se han reconocido múltiples fuentes de información fuera de lo que el positivismo nos señalaba como únicas reveladoras de la verdad histórica. Prensa, radio, televisión, Historia oral, cine y, en última instancia, el internet conforman los recientes manantiales de datos contemporáneos. Son, al final de cuentas, herramientas complementarias que, aunque puedan perturbar por su apariencia, en palabras de Rosenstone (2005: 91), animan al historiador a salir de la biblioteca.

En la sociedad del espectáculo que nos rodea, el cine encuentra cabida. Si lo consideramos como un contenedor de realidades sociales, capaz de incrustar mentalidades o de persuadir decisiones, es deber del historiador visualizarlo y analizarlo, buscar en él las ideologías que enarbola para esconder o deformar la realidad o, en su caso, crear una nueva (Amador, 2002: 24), como fue el caso del cine propagandista de Goebbels en la Alemania nacionalsocialista. En otras palabras, tendríamos que hablar del cine como un vasto laboratorio que al historiador le ayuda a meditar con mayor amplitud sobre los conflictos sociales, políticos, religiosos y culturales (Cabrera, 1999: 15).

El lenguaje, como menciona Gadamer, sea cualquiera que este fuera, produce sentido (Gadamer, 1999: 144-145). Por tanto, los lenguajes cinematográficos tienen un norte al que siempre apunta su brújula, que está determinado tanto por las posturas que los cineastas toman en relación con el mundo, su forma de verlo, de convivir con él y de mimetizarse en su ambiente, como por los múltiples sentidos que el espectador genera al interactuar con las películas. Al hablar de lenguaje cinematográfico, entendamos el cine como agente de la historia; en palabras de Marc Ferro, es instrumento a la vez que documento, y plantea discursos de diversa índole, generando significados doctrinarios que dan testimonio de contextos 


\section{Balajú}

sociohistóricos que le permiten ser (Alvira, 2011: 139). El cine es pura filosofía en tanto es reflexión sobre el ser humano y la manipulación que este hace de la realidad.

Guillermo Michel considera que la percepción estética de las películas está relacionada con la personalidad de los espectadores y que la manera en que se perciben a sí mismos determina su percepción de las películas; a eso responde el que muchas personas tengan comentarios diferentes respecto de un mismo filme (Michel, 1998: 214). En la misma línea se encuentran las reflexiones de Pierre Sorlin, quien piensa al público como ente capaz de determinar, mediante su consideración, la etiqueta que un filme merece ya que "la atención prestada a los filmes y a la sensibilidad y su contenido ideológico varían de un medio a otro, según las readaptaciones, las redistribuciones de la materia fílmica realizada por los espectadores" (Sorlin, 1985: 23).

Aquí es donde aparece el debate sobre cómo interpretar una película desde la mirada del historiador porque, en última instancia, somos también espectadores. Rosenstone señala que los investigadores tienen exigencias básicas de verdad y de verificación, por lo que se presenta el problema específico de la adaptación. A su entender, los historiadores ponen en entredicho los testimonios y las libertades creativas que son tomadas por los cineastas porque las consideran interpretaciones ficticias. Rosenstone llama a no tener miedo de que el cine represente el pasado histórico porque, pese a las necesidades narrativas que le son particulares, el cine no difiere mucho en cuanto a especulaciones también hechas por la historia escrita (Rosenstone, 2005: 92-93, 98-99). Sorlin, por su parte, halla otra problemática, relacionada con las emociones. En Sociología del cine, expone que el historiador se perturba también por los sentimientos que le despierta la película, considerándolos un escollo que altera las observaciones. Su resolución es simple: el juicio se puede ver afectado por las emociones, pero en lugar de negarlas, se deben aceptar y analizar su origen (Sorlin, 1985: 32).

Entonces, ¿cómo podemos estudiar un filme? La propuesta aquí manejada es olvidarnos un poco de las disecciones más puntillosas al estilo de las deconstrucciones derridianas, pero sin caer en la trampa de la totalización o vista global. Para el caso en concreto de 'Ora sí: ¡Tenemos que ganar!, es más menester advertir las construcciones discursivas que se tejen dentro del filme (los enlaces que los personajes tienen consigo mismos y su interacción con los otros) y fuera del mismo (la interpretación del anarquismo por parte de los autores y su plasmación en el guion y, por tanto, el argumento). 


\section{Balajú}

El intento será trasladar el discurso de 'Ora sí: ¡Tenemos que ganar! a una dimensión filosófica, a la usanza de Marc Ferro, no tomando en cuenta lo que atestigua, sino su acercamiento sociohistórico (Alvira, 2011: 139). En otras palabras, para lograr un estudio comparativo entre lo que Flores Magón decía y lo que Kamffer representó, resulta necesario no cuestionar el desarrollo histórico en el marco y especificidad de la trama, para concentrarse en los elementos que alegorizan el anarquismo y la ética libertaria contenidos en las líneas de Regeneración.

Desde el punto de vista de Cabrera, para que una película sea pensada desde la filosofía, debe cumplir con tres requisitos: representar algo mediante la racionalidad y la afectividad; producir algún tipo de impacto al contactar con ella; manifestar experiencias de la condición humana (Cabrera, 1999: 18-21). 'Ora sí: ¡Tenemos que ganar! desempeña tajantemente cada una de las modulaciones: trata de racionalizar las acciones de los personajes, sin que el director intente censurar sus dinámicas de expresión (más allá de las relaciones que se establecen dentro de la trama), y ello encuadrado en la emotividad que significa la situación de miseria que atraviesan los mineros. El contacto que el filme establece con el espectador va más allá del gusto o disgusto por lo que representa; en su lugar, motiva a cavilar las complejidades expuestas. Finalmente, brinda a los espectadores un metraje sobre el posicionamiento del hombre en un mundo donde la represión militar, la explotación laboral y el intervencionismo extranjero en la economía son el pan de cada día; y se cierra el círculo con el abordaje de temáticas concernientes al odio, al amor, a la intolerancia, el miedo, la ira, la impotencia y, sobre todo, la insurrección y los deseos de libertad.

Como último señalamiento metodológico, para fines prácticos del trabajo, se usará la categoría floresmagonista para referir al ideario y la práctica política de Ricardo Flores Magón, pese a la renuencia del anarquismo por someter su filosofía a prefijos de personalidad. Como bien lo sostiene Marco Antonio Samaniego, los anarquistas mexicanos pensaban que los personalismos eran absurdos para un verdadero revolucionario, considerando que su uso debía limitarse a los políticos (Samaniego, 2015: 35). En la película, el personaje del "Apóstol” también hace referencia a la renuncia que se debe hacer al protagonismo y al vanguardismo.

\section{La apertura cinematográfica que permitió nuevos productos audiovisuales}

Temporalmente, la década de los setenta resulta de suma importancia en el devenir político mexicano. Hasta entonces, los mandatarios priistas de la posrevolución habían mantenido un 


\section{Balajú}

control fuerte sobre los campos culturales, sociales y políticos. Christian Mendoza lo desglosa con suma lucidez: el totalitarismo oficialista había intentado sepultar a todos los opositores del régimen, desde los disidentes periodísticos hasta los practicantes de las filosofías entonces radicales, aniquilando a los movimientos de guerrilla campesina liderados por Lucio Cabañas y Genaro Vázquez (Mendoza, 2014: 4).

Pero, con el salto de década, una vez concluido el mandato de Gustavo Díaz Ordaz, comenzaron a presentarse en la palestra política una serie de inconformidades sociales, gran parte nacidas por el recuerdo de la matanza del 2 de octubre de 1968 en Tlatelolco. Luis Echeverría, electo sucesor de Díaz Ordaz, asumió la presidencia en 1970 y de inmediato contrastó su figura con la de su antecesor, entendiendo la necesidad de transmitir una imagen diferente. Tras el halconazo del $71,{ }^{2}$ su política consistió en abrirse ante el resto de los países tercermundistas para mostrar una cara democrática: liberó a los presos del movimiento estudiantil, recibió a Salvador Allende en 1972, la asociación de obreros y campesinos independientes no fue bloqueada, la represión contra la radicalización marxista-leninista no hizo tierra quemada (Pascual, 2016: 22-24). La pugna por democratizar las contiendas electorales se avivó cuando José López Portillo ganó los comicios federales como único candidato registrado. El descontento obligó al gobierno a impulsar una Ley Electoral en 1977, esperando incrementase el número de contendientes en los sufragios posteriores, dejando que incluso el Partido Comunista se registrara (Gutiérrez, 2000: 160). En suma, la intentona consistía en dar apertura al sistema político para que la participación ciudadana creciera en relación con los sexenios pasados, demostrando así que México era un país democrático, a diferencia del resto de Latinoamérica, para ese momento presa del ascenso de dictaduras militares de Jorge Videla en Argentina (1976), Hugo Banzer en Bolivia (1971), Augusto Pinochet en Chile (1973) y Juan Bordaberry en Uruguay (1971), así como del fortalecimiento de otras ya establecidas, entre ellas las de Atanasio Somoza en Nicaragua y Alfredo Stroessner en Paraguay.

Para el caso del cine, el proceso de retroceso en la censura se dio simultáneamente a la construcción de la renovada imagen nacional. Desde la década de los sesenta, el arte se entremezcló fuertemente con la política revolucionaria, presentando muchos elementos utópicos próximos a los cambios sociales ocurridos a lo largo del mundo (King, 1994: 103-

\footnotetext{
${ }^{2}$ Se refiere a la masacre de estudiantes a manos de un grupo paramilitar llamado los Halcones, actuando al servicio del Estado, el 10 de junio de 1971, en la Ciudad de México [N. de la E.].
} 


\section{Balajú}

104). Ciudad Universitaria ${ }^{3}$ en vísperas del 68 era un espacio de libertad creativa. A su alrededor se congregaban poetas, dramaturgos, músicos y pintores. Los alumnos del Centro Universitario de Estudios Cinematográficos siguieron de cerca la movilización y decidieron salir a las calles con cámara en mano para registrar los acontecimientos. Entre la camada de jóvenes realizadores se encontraba Raúl Kamffer (Ramírez, 2015: 22).

Por estas fechas, el artista José Luis Cuevas pintó en la Zona Rosa su autorretrato al lado de imágenes inspiradas en la Guerra de los Seis Días. A la obra la bautizó como Mural efímero, concebida como una crítica al protagonismo del muralista David Alfaro Siqueiros. Kamffer realizó una pequeña producción con el mismo título, a la que acompañó de música de Deep Purple e incrustó una narración que rezaba “La juventud combatió con rosas/ la juventud se enterró sin flores/ se quemó en los hornos militares/ se castró/ y aun muerta está violada/ pero no se crea que hemos olvidado/ no hemos dejado de morir" (Estrada y Noyola, 2016: 17). Pese a ser filmada durante el 68, Mural efímero fue estrenada hasta 1973; por su largo proceso de posproducción, pudo integrar fotos de los muertos de Tlatelolco (Ramírez, 2015: 23). Lo revelador del asunto es que deja entrever que Kamffer se encontraba interesado en la política desde sus primeros pasos cinematográficos.

La libertad de expresión enarbolada por Luis Echeverría permitió que, además de Kamffer, otros realizadores manufacturaran trabajos independientes con tintes radicales para la época; tal es el caso de Francisco Bojórquez, Paul Leduc, Leobardo López Arretche y Federico Weingartshofer. (King, 1994: 194). ${ }^{4}$ Para administrar la producción de películas de ficción y documentales, el presidente puso a su hermano Rodolfo Echeverría al mando del Banco Cinematográfico, lugar desde donde propuso racionalizar la economía para que el Estado se permitiera apoyos financieros para el cine. Los temas de la censura, de la promoción de nuevos cineastas y del impulso al cine comercial/industrial con rentabilidad también formaban parte del programa político (Pascual, 2016: 26-29). Bajo su gestión se fundó la Cineteca Nacional y el Centro de Capacitación Cinematográfica, concebido como una segunda escuela para cineastas.

\footnotetext{
${ }^{3}$ Campus de la Universidad Nacional Autónoma de México (UNAM), ubicado en la zona sur de la capital nacional [N. de la E.].

${ }^{4}$ López Arretche, director del documento colectivo El grito, sobre el movimiento estudiantil del 68 y filmado por estudiantes de la UNAM (Kamffer entre ellos), murió por mano propia en julio de 1970. El documental, oficialmente suprimido, circuló de manera clandestina hasta su estreno público en 1976: muestra de la apertura echeverrista señalada aquí [N. de la E.].
} 


\section{Balajú}

Entre 1970 y 1977, periodo que Eduardo de la Vega (1991: 52) llama "Intervención estatal en la producción", se produjeron y estrenaron filmes con intereses revolucionarios, pero que siguen una línea de retórica nacionalista y antiimperialista propia del gobierno echeverrista. Los casos más emblemáticos son los de Canoa: denuncia de un hecho vergonzoso, dirigida en 1975 por Felipe Cazals, y Reed: México insurgente, de Paul Leduc en 1976 (King, 1994: 196197 y 200). Las fronteras también se abrieron para la entrada y salida de cinematografía; el documental 2 de octubre. Aquí México, rodado por Óscar Menéndez, se proyectó en Francia, Alemania, Italia, Dinamarca, Suecia e Italia. ${ }^{5}$ A la inversa, al país llegó el cineasta argentino Raymundo Gleyzer, encargado de grabar México, la revolución congelada, en 1973, una cinta que abrió la puerta para que se pudiera filmar sobre rebeliones y despojo en México (Estrada y Noyola, 2016: 21-27). Es, precisamente, sobre esta temática que versa 'Ora sí: ¡Tenemos que ganar!

\section{Kamffer y la producción de 'Ora sí: ¡Tenemos que ganar!}

Durante su carrera cinematográfica, Raúl Kamffer se interesó en cuestiones sociales, apegado siempre al cine independiente. Su debut se dio en 1967 con Preparatoria 100 años. Un año después rodó Fiesta de muertos y Mural efímero. Enmarcado en la filmografía de 16 milímetros, grabó Mictlán o la casa de los que ya no son, y Ana y Diana (ambas de 1969), El juego de Zuzanka (1970) y El perro y la calentura (1973). Su filmografía la completan Energomex (1975) y Parto solar 5 (1979), y, en su rol de productor, Semana Santa entre los coras (1971).

La narrativa que empleaba en sus películas, según Toni Kuhn, se relacionaba con el choque de las culturas, las conflictividades sociales y lo político pensado desde lo independiente (Lozano, 2018: 11). Sobre esto, y para entender mejor su perspectiva, hay un pequeño relato que la Revista de la Universidad de México publicó. Bajo el título "El templo es un bosque de quetzales. Los sacerdotes se apiñan en las gradas”, Kamffer redacta un ensayo en el que plantea la manera en que el misticismo mexica y la posterior cristiandad hacen mella en la cotidianeidad de los allegados a Tlatoani. El narrador, Jesús de Moctezuma, rememora los años previos al arribo de los ibéricos, época en la que los macehuales se sometían a dioses como Huitzilopochtli, sedientos de guerra y de sacrificios. Moctezuma Xocoyotzin temía a los

\footnotetext{
${ }^{5}$ Cabe señalar que, si bien esto pasó gracias al activismo del director y a su relación con el filósofo Jean-Paul Sartre, el gobierno no impidió su exportación.
} 


\section{Balajú}

augurios y a sus sueños proféticos en los que Quetzalcóatl regresaba a reclamar su reino, uno en el que la libertad, la alegría, el amor carnal, la riqueza y el pecado serían permitidos para goce de todos los aztecas. Intentando impedir el nuevo orden, se volvió un gobernante sádico, sumergido en oscuros pensamientos, abandonado a la reflexión personal, ignorando los consejos de los demás nobles miembros de su corte. Después de pasar nueve meses en intensa meditación, hizo la guerra a una escala nunca vista, mandó confiscar riquezas, alzar cárceles y sacrificar en masa a lo largo de tres semanas ininterrumpidas. Su deseo último era también ser sacrificado con altos honores, pero el anhelo se truncó cuando un mensajero llegó a sus aposentos anunciando el regreso de Quetzalcóatl. En retrospectiva, Jesús de Moctezuma hace un balance de la antigua y nueva dictadura, concluyendo que con los españoles nada cambió porque ahora viven “... con el temor y la muerte cercándonos, además estos extranjeros introdujeron la tortura, las plagas, el dinero [...] en el templo mayor ya no se sacrifican guerreros, ahora se descuartizan vivos a los idólatras" (Kamffer, 1973, 39).

Pese a tratarse de un relato de ficción ambientado en un proceso histórico, el texto demuestra los intereses del autor, como la relación del subordinado con los mandatos del regente y los sentimientos y pensamientos de los ignorados. Eduardo de la Vega comenta que, a mediados de los setenta, Kamffer comenzó a interesarse en el estudio del anarquismo, en específico del movimiento liderado por Ricardo Flores Magón; esto después de encontrarse en una biblioteca el libro Sembrando ideas, que recopilaba fragmentos de Regeneración; su lectura dio origen a lo que sería el primer borrador de 'Ora sí: ¡Tenemos que ganar! coescrito con Leonor Álvarez (Díaz, 2005: 326).

La suma de sus intereses y sus recientes lecturas lo llevaron al set de rodaje. Teniendo Puebla y Real del Monte como locaciones, y financiada por la UNAM, la película fue un cúmulo de innovaciones y caos. Toni Kuhn, cinematógrafo que colaboró con Kamffer en siete producciones, cuenta que las batallas se grabaron con cuatro cámaras montadas y que, para las escenas más difíciles, se integraron elementos del cine documental, destacando la necesidad de grabar cámara en mano las escenas en el interior de la mina. La cercanía del lente con los actores reflejaba que el director "tenía una visión de la política muy personal" (Lozano, 2018: 11). La Academia Mexicana de Artes y Ciencias Cinematográficas elogió el producto final, galardonando a Kuhn con el Ariel a mejor fotografía, a Kamffer como mejor director, a Juan Mora Catlett por su trabajo en la edición, y a 'Ora sí: ¡Tenemos que ganar! con el premio de mejor película. 


\section{Balajú}

\section{Discurso floresmagonista}

Flores Magón, seguramente, ha sido uno de los literatos anarquistas más radicales, no solamente en México sino también fuera de sus fronteras. Nació en 1873; era aún un niño cuando Mijaíl Bakunin murió; ocho años antes de su alumbramiento, falleció Pierre-Joseph Proudhon. Pero Piotr Kropotkin pereció apenas un año antes que Ricardo, mientras Emma Goldman fue su contemporánea y le sobrevivió. Estos datos permiten contextualizar su vida y contrastarlo con los discursos ácratas más fuertes que le fueron contemporáneos. El anarquismo floresmagonista retomó aspectos económicos de Proudhon, sobre todo los relativos a la noción de propiedad privada; de Bakunin, rescató las posturas incendiarias respecto a los movimientos revolucionarios y la actitud a tomar en relación con el gobierno. Precisamente, el número 57 de Regeneración del sábado 30 de septiembre de 1911 lanza una proclama en contra de toda autoridad y de los que a su entender eran los ricos, pidiendo tajantemente que mueran (Flores Magón, 1995: 186).

Fernando Zertuche lo distingue como "un heterodoxo radical que por encima de la retórica de la época expresa cargos directos al poder" (Zertuche en Flores Magón, 1995: 19). Ricardo, junto con su hermano Enrique, fundaron el Partido Liberal Mexicano (PLM, en adelante) en 1905, que tuvo entre sus filas a otros destacados anarquistas mexicanos de la época: Librado Rivera, Anselmo Figueroa y Práxedis Guerrero. El programa pretendido por el PLM tenía puntos que resultaban atractivos para los opositores al régimen porfirista imperante en ese momento: 1) rechazo al orden establecido, su propuesta era crear un nuevo mundo para desplazar al existente; 2) realzar valores y creencias laicas acordes y coherentes a los deseos destructivos y constructivos del anarquismo; 3) clarificación de los medios requeridos para triunfar, como la activa agitación social mediante la propaganda y organización comunal para violentar al Estado. Entre líneas aparecían vagas pistas sobre el futuro a seguir, en el renovado orden de cooperación fraternal (Gómez, 1977: 15-16).

Ricardo Flores Magón pisó la cárcel en no menos de nueve ocasiones, tiempo de prisión que le sirvió para labrar su discurso libertario. Con el pasar de los años, en su pluma se notó una bayoneta más afilada, menos dubitativa, pese a que en un principio no era del todo radical (Abad de Santillán, 1978: 24-25). El salto es perceptible si se leen los textos magonistas (escritos junto a su hermano Jesús) contenidos en la colección Batalla a la dictadura, compilación a cargo de Martín Luis Guzmán, y se comparan con el resto de los escritos 


\section{Balajú}

manufacturados en las proximidades de 1910. En un artículo fechado el 15 de abril de 1901, los hermanos Magón reniegan del calificativo de revolucionarios, posicionándose en contra de los levantamientos armados, considerando que la verdadera vía emancipadora no va de la mano con la fuerza de las balas y de los fusiles, sino de la educación, único garante de la paz y de la libertad (Flores Magón, 1967: 68-75).

Ricardo planeó, junto al seno del PLM, iniciar un movimiento revolucionario en contra de Porfirio Díaz, fijando distintas fechas para su consumación. Pero la intención de los ácratas no consistía en prender la mecha de una insurrección cuyo único objetivo fuese derrocar a Díaz en pro de poner a otro individuo en la silla presidencial; Flores Magón, por el contrario, aseguraba que ese sería un acto delictivo en contra de la dignidad del pueblo mexicano, ya que el deber de los revolucionarios era sepultar cualquier régimen, para dotar a los campesinos y obreros de libertad económica, verdadero interés de las masas (Flores Magón en Abad de Santillán, 1978: 69). Sobre la idea de libertad económica, también nos dice que debe ser una idea presente en el cerebro al momento de movilizarse en contra de los rectores del poder. La venganza y la cólera no deben ser motivos ciegos, sino razones para dignificar a los proletarios, para conquistar la tierra y para colectivizarla (Flores Magón, 1983: 136-139).

Para ejemplificar de mejor manera la postura política de Ricardo Flores Magón, se recuperan algunos de sus pensamientos transcritos por Diego Abad de Santillán: "La tierra es de todos [...] la propiedad territorial está basada en el crimen y, por lo mismo, es una institución inmoral. Esta institución es la fuente de todos los males humanos [...] el tirano no es un producto de generación espontánea: es el producto de la degradación de los pueblos..." (Flores Magón en Abad de Santillán, 1978: 70-72). Flores Magón reconoció en la autoridad al más despreciable de los enemigos del hombre, puesto que encarnaba el salvajismo y la barbarie, capaz de asesinar y de llenar el territorio de sangre con tal de mantenerse en pie. A su juicio, los gobiernos utilizan las leyes a su favor, para crear un círculo de tiranía (Flores Magón, 1967: 178-181).

Como ya se dijo, para 1910, la violencia en el discurso floresmagonista reemplazó las timoratas posturas que tuvo una década atrás. En el ejemplar de Regeneración del 3 de septiembre de 1910, solicita a los obreros empuñar los fusiles para interrumpir la denominada pax porfiriana, siendo la revolución algo necesario para abolir el despotismo, pese a la sangre y las lágrimas que pudieran ser derramadas, ya que la sangre inundaría los cubiles de los chacales, fungiendo como el líquido que los ahogase (Flores Magón, 1983: 11-12). Siete días 


\section{Balajú}

después, en Regeneración se pueden leer cosas sobre la importancia de la prensa disidente, en particular las que atañen al uso ideológico de los periódicos, que sirven de lazo entre el ser y la conciencia revolucionaria. El individuo se vuelve insumiso a través del conocimiento de estos semanarios y se aferra al derecho sagrado de rebelión, dispositivo del espíritu combativo, capaz de derribar todas las Bastillas de la humanidad. Es en este ejemplar en el que inscribe una de sus más famosas frases: "La rebeldía es la vida; la sumisión es la muerte" (Magón, 1983: $18)$.

Antes de dar paso al siguiente apartado, hablar de la mujer dentro el pensamiento floresmagonista resulta menester para la propuesta final y comparativa del ensayo. En Regeneración del 24 de septiembre de 1910, la pluma de Ricardo Flores Magón escribe sobre lo imperante de la revolución para que reparta muerte entre los poderosos. Pero más que una incitación, el artículo se ocupa de la condición de la mujer en la historia, rememorando sus infortunios por ser vista como un ser inferior al hombre; desde las sociedades más primitivas, pasando por las civilizaciones clásicas, llegando hasta la época cristiana, el varón había visto en las mujeres a un objeto para satisfacer sus necesidades laborales y sexuales. Magón dice que esto es un lastre en el pensamiento humano, puesto que todos son iguales; naturalmente nadie está sobre nadie, por lo que ritos como el matrimonio le parecen un caso de prostitución legislada y autorizada por los funcionarios de la ley, respaldando un círculo vicioso de machismo. El fundador del PLM pide a las féminas apoyar la insurrección, respaldando a los padres, hijos, hermanos, esposos, mediante las actividades que les sean fáciles de desempeñar. Sin embargo, cabe decir que Flores Magón no ve cualidades bélicas en la mujer, y la limita a ser un apoyo moral del hombre, una interlocutora que señale como cobardes a quienes se nieguen a guerrear (Flores Magón, 1983: 22-26).

\section{'Ora sí: discurso floresmagonista en el cine}

La película, como se evidenciará en las siguientes líneas, contiene una amplia cantidad de referencias filosóficas presentes en distintos discursos políticos. En menos de cinco minutos, un corrido ya detalla las primeras pinceladas ideológicas presentes: "Vale más vivir de pie que morir arrodillado", entona la voz del cantante. El tema de la muerte es recurrente en toda la trama. Adela (interpretada por Patricia Reyes Spíndola) abre la cinta con un soliloquio en la tumba de su fallecido esposo. Ella refiere que el difunto era reaccionario (dígase, contrarrevolucionario), a diferencia suya que, pese al aparente dolor que la aqueja, está 


\section{Balajú}

dispuesta a pelear por la revolución. El resto de los personajes, obreros en su mayoría, aluden a que es mejor dejar de existir, combatiendo por los derechos de los productores, antes que perpetuar el estado de miseria que los aqueja, porque la mina representa una tumba en vida, misma que no desean heredar a sus hijos, por lo precario que es ser minero, trabajo que consideran poco fructífero y digno. Dos de los proletarios, al momento de descender a las cavernas plateras, recuerdan una frase de Práxedis Guerrero que reza "Vivir para ser libres o morir para dejar de ser esclavos", y con ella puntualizan su sentir respecto a la muerte.

El enemigo de las clases populares es encarnado por el empresario estadounidense $\mathrm{Mr}$. Creel, quien es dueño de la mina. El señor Creel se muestra renuente a invertir su dinero en el rescate de un grupo de excavadores atrapados luego de un derrumbe en las galerías subterráneas, argumentando que es la primera vez que cuenta con un capital propio, luego de sufrir económicamente en su juventud. Constantemente displicente, adopta una postura que contraviene las necesidades de sus trabajadores, mismos que de a poco engendran odio hacia su persona. En algunas secuencias se le mira prefiriendo ingerir licor en lugar de administrar el salvamento de los sepultados en los escombros. Asimismo, niega el apoyo a los familiares, con el argumento de que existen deudas que la gente debe cubrir a la empresa. Tampoco paga en dinero sonante, ya que utiliza el maíz como moneda de cambio.

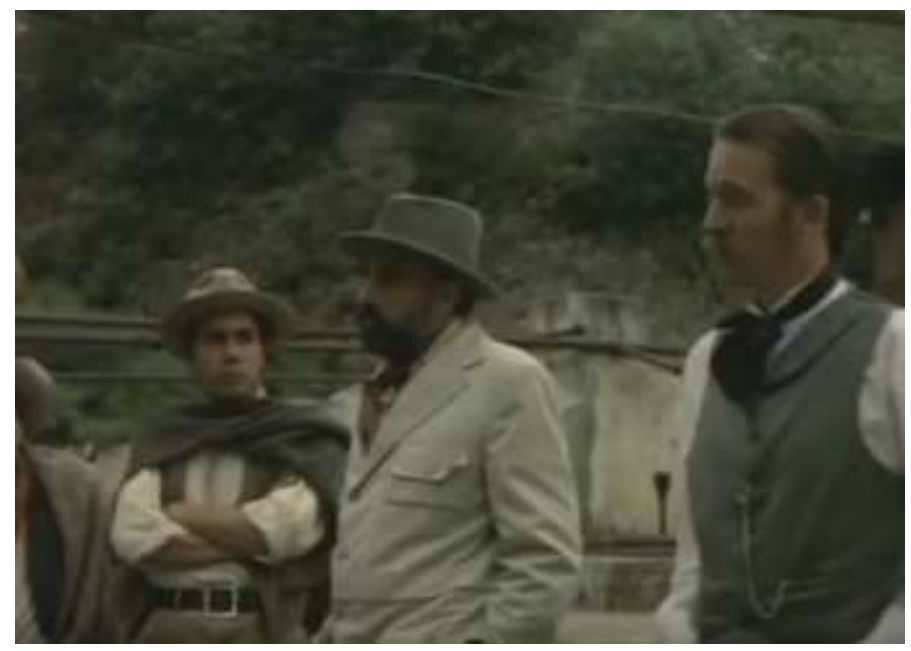

FOTOGRAMA 1. Mr. Creel hablando con los mineros, negándose a pagarles si no trabajan en la mina colapsada.

El aglomerado de vejaciones hace que los obreros se replanteen su existencia. En un primer momento son reacios a participar de la vía armada, puesto que son conscientes de las implicaciones que trae consigo sumarse a los revolucionarios. En una de las escenas, una madre 
reprende a su hijo por dicha situación: el vástago quiere partir a la guerra pese a la oposición de la progenitora. Ella, para impedir su deseo, utiliza el chantaje moral, enarbolando la palabra de Cristo. Otros personajes son más discretos y únicamente enlistan las responsabilidades hogareñas que tienen: cumplir con los roles de padre y esposo (llevar sustento a la casa, apoyar con la educación de los niños, intervenir en la defensa de su familia), aunque también hay los que aceptan temer a la guerra, tanto por las balas que pueden recibir como por las frías celdas que les esperan en caso de ser arrestados in fraganti.

Respecto a las dudas que genera la insurrección popular, circulan los planteamientos libertarios. En las reuniones proletarias, continuamente se alzan voces que cuestionan la utilidad del floresmagonismo: ¿cuándo ha funcionado una sociedad anarquista? ¿Cómo se pueden organizar las personas sin depender de una autoridad? ¿Es posible un mundo sin jerarquías ni administradores? ¿Podrán dejar de existir los constructos sociales y culturales hasta ahora establecidos? ¿Realmente no son necesarios los cuerpos castrenses para salvaguardar la paz y el orden? Estas son algunas de las preguntas que se hacen las personas. Aquí surgen las figuras de los ideólogos floresmagonistas que quieren dar respuesta a todas las interrogantes de las clases bajas.

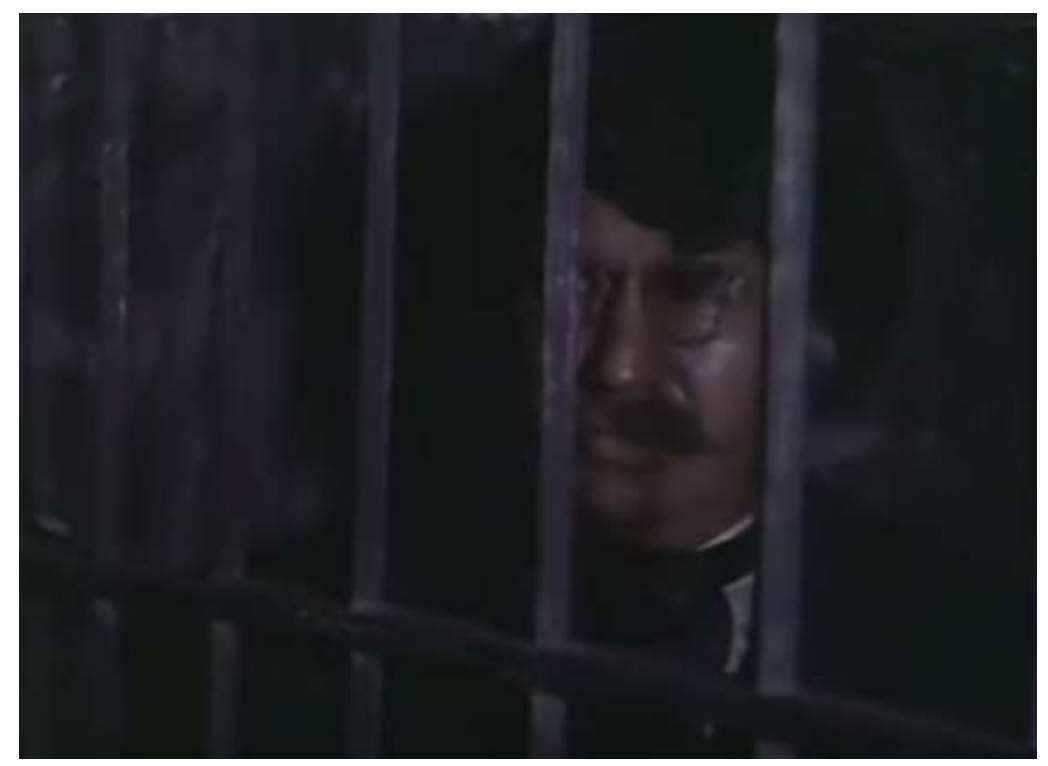

FOTOGRAMA 2. Representación de Ricardo Flores Magón, preso durante el momento en que se desenvuelven los acontecimientos narrados.

Si bien Ricardo Flores Magón no aparece más que en un par de escenas (estando preso en ellas), el lugar de revolucionario práctico es tomado por el personaje de "el Apóstol”, también 
llamado "el Catrín", un hombre que se encarga de difundir los ejemplares de Regeneración entre los desvalidos, llevando consigo la filosofía anarquista, con la que intenta motivar a los mineros a tomar medidas en contra de Mr. Creel y de la explotación en general. Sus postulados se resumen en varias frases y en las contestaciones a los cuestionamientos antes mencionados: el alcoholismo refuerza las cadenas de los oprimidos, al mantenerlos en un estado embrutecido que ayuda a perpetuar la explotación del hombre por el hombre; el principal detonante de la desigualdad social y de las desgracias humanas se llama propiedad privada; los patrones y sus defensores deben dejar de existir para permitir la libertad; las vanguardias revolucionarias no se deben permitir; aunque en su apariencia sean subalternos, en el fondo son falsas críticas a lo establecido, y pueden llegar a cimentar una nueva tiranía.

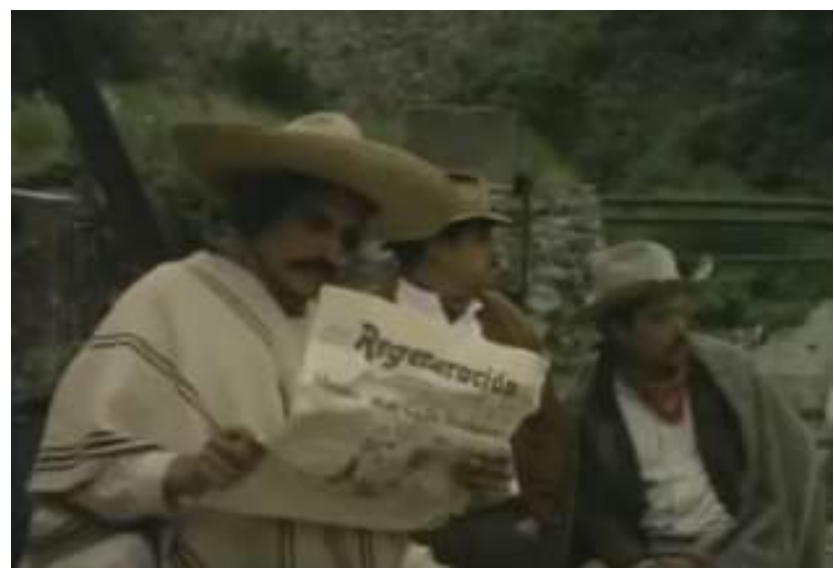

FOTOGRAMA 3. Los mineros leyendo un ejemplar de Regeneración.

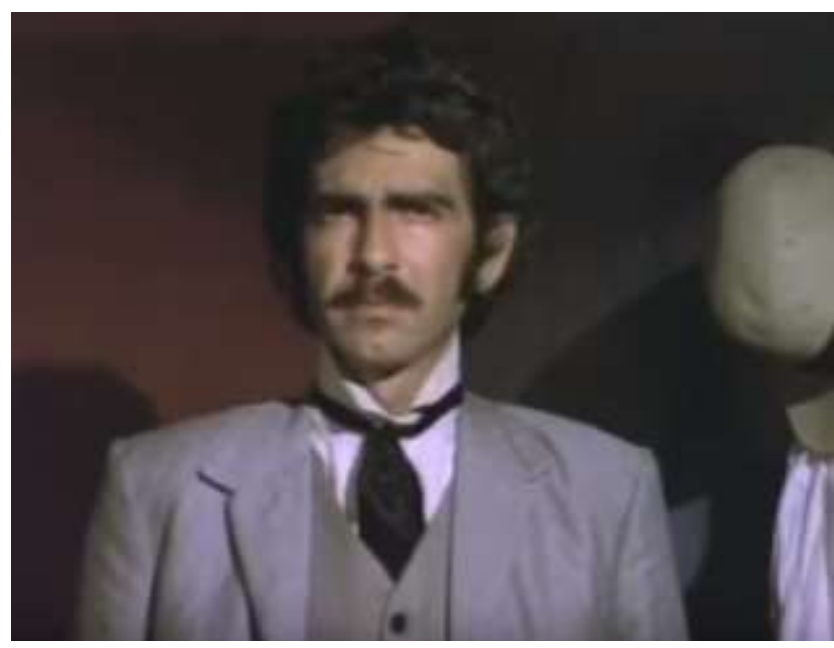

FOTOGRAMA 4. "El Apóstol" explicando a los mineros los principios organizativos del anarquismo, haciendo hincapié en la necesidad de eliminar al gobierno y al Ejército. 
Las propuestas que "El Apóstol" dispone, bajo la influencia floresmagonista, son: hacer un cambio de categorías distintivas, pues los floresmagonistas no se manejan con nombres jerárquicos ni con taxonomía marxista (camaradas); en su lugar, se nombran entre sí como compañeros; la toma de decisiones se realiza en asambleas con votación directa, implementado el debate y la exposición respetuosa de posturas; la violencia revolucionaria es la mejor vía para derrocar los cacicazgos; la organización social sin administradores estatales es posible poniendo en práctica el cooperativismo; la propiedad privada será reemplazada por la propiedad comunal, en la que cada cual trabajará de acuerdo con sus capacidades, aportando al bien colectivo sin coacción; si se da pan por igual a todas las personas no existirá la necesidad de delinquir, por lo que la penitenciaria y los cuerpos policiales se volverán obsoletos; el armamento y los pertrechos pasarán a manos del pueblo, mismos que le permitirán defenderse de la reacción, de las vanguardias y de los ejércitos y milicias gubernamentales.

Una de las características más llamativas de la película es la que concierne al papel de la mujer en la revolución. Es bien sabida la presencia de féminas en las huestes insurrectas, apoyando a los hombres en los combates. Estas recibían el nombre de soldaderas. Pero Raúl Kamffer nos presenta un arquetipo diferente: la mujer floresmagonista no determina su accionar en relaciones desiguales con el hombre; todo lo contrario, Adela, la tía Eduviges o la sirvienta del matrimonio Creel no dependen de nadie para apoderarse de la iniciativa de pelear en contra de los militares. Al principio, su ayuda se reduce al apoyo doméstico de los varones en la higiene y en la economía, aportando a los gastos mediante la venta de tamales.

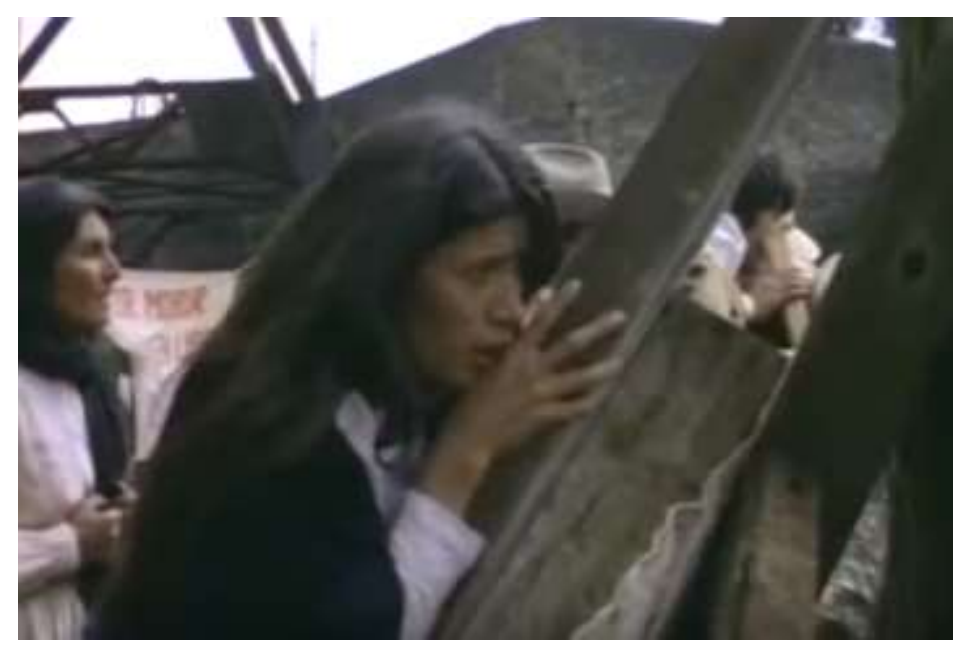




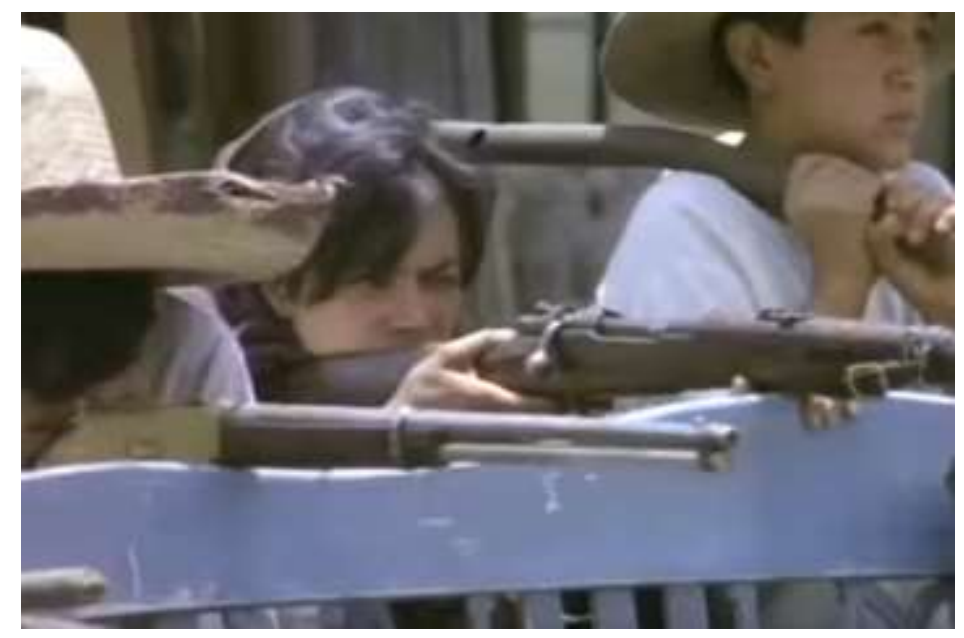

FOTOGRAMAS 5 y 6. Mujeres tomando parte de la defensa de las barricadas y del enfrentamiento en contra del ejército. Algunas permanecen a la expectativa, otras blanden armas.

Conforme avanza la trama, las mujeres actúan más radicalmente: expropian la tienda de raya de la mina, se agrupan para marchar sobre la hacienda y tomarla bajo su custodia, disponen sus dineros para adquirir armas y practicar la puntería para cuando sea menester abrir fuego contra los soldados, se muestran capaces de estructurar discursos políticos sumamente articulados, intervienen en favor de los detenidos y, finalmente, son el factor determinante en el triunfo de los pobladores. La sirvienta de los Creel siembra explosivos en una canasta y logra matar a los dueños de la mina; la tía Eduviges da muerte al oficial en jefe del ejército, aunque este acto le acarrea la muerte (a destacar que su velación se efectúa con una bandera revolucionaria envolviendo su cuerpo inerte).

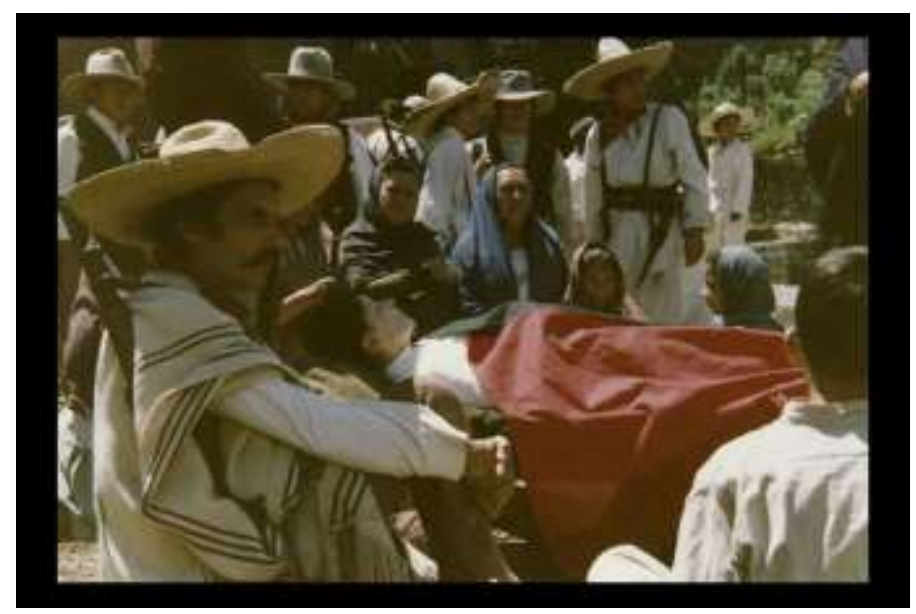

IMAGEN 2. Funeral de la tía Eduviges, envuelta en una bandera roja. Obtenida de https://n9.cl/6w34n 
El último punto por abordar respecto al contenido político de la película es la presencia de medidas restrictivas en contra de la filosofía disidente. Las noticias revolucionarias vertidas en Regeneración, así como sus peticiones de tierra para los campesinos y horca a los patrones encuentran oídos sordos entre la población. Esto, se entiende, es gracias a la poca educación política que hay en la sociedad, ya que para los terratenientes es mejor mantener ignorantes a sus sumisos. Sin embargo, el ideario anarquista sí significa un peligro, por lo incendiario de su discurso (que, como vemos, al final de cuentas sí influenció a los obreros mineros), lo que obliga a las autoridades a tomar cartas en el asunto. La represión parte del sabotaje y la destrucción de las imprentas que surten a los periódicos rebeldes: la policía hace cateos de materiales propagandísticos y arrasa y desmantela las casas editoriales; pero el encierro es la principal herramienta de sometimiento que el gobierno emplea en contra de los insurrectos. Ricardo Flores Magón es, en efecto, detenido y hecho prisionero, aunque ello no impide que sigan circulando sus manuscritos (se deja ver el apoyo que otros presos le dan, al facilitarle papel y tinta para que pueda continuar "sembrando ideas").

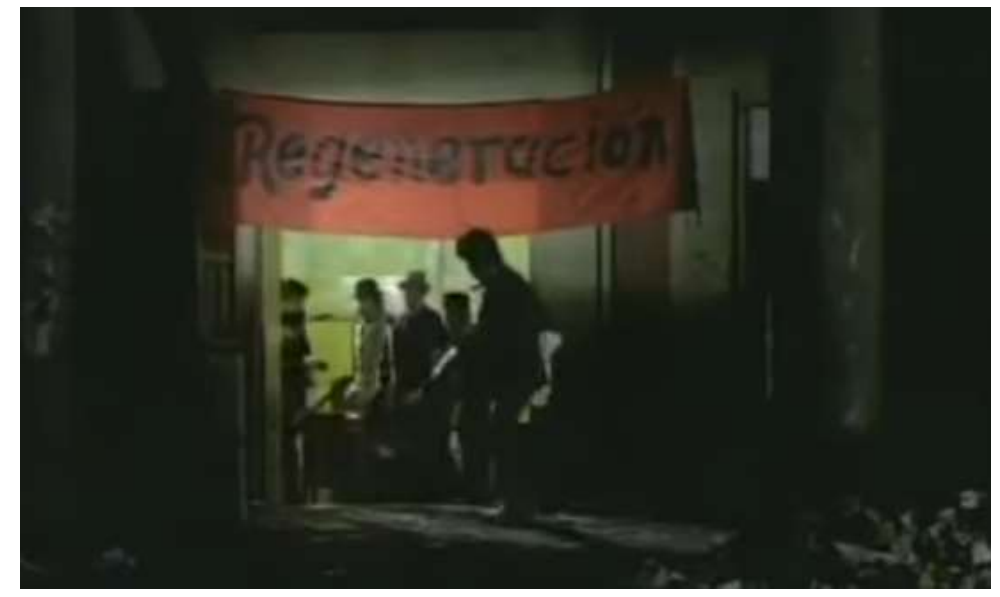

FOTOGRAMA 7. La casa-imprenta de los anarquistas que editan Regeneración siendo cateada por la Policía Federal.

Dentro de los reos también se encuentra "el Apóstol", aunque su estancia tras las rejas es efímera. Las mazmorras de la burguesía (como son llamadas por los personajes) quedan cortas para contener la revolución, y se hace necesaria la intervención de las fuerzas del orden. Previamente, Mr. Creel realiza despidos como prevención coercitiva, pero resulta infructífera; también la esposa del señor Creel intenta disipar el malestar entre los mineros al repartirles pastel. En el clímax, la tropa es el recurso último para someter la huelga; pero, pese a estar 


\section{Balajú}

mejor armados, los soldados son derrotados, para dar paso a la llegada del "Apóstol” y otros revolucionarios, festejando todos con salvas a Ricardo Flores Magón.

\section{Confluencias y rupturas}

Ya expuestas ambas dimensiones del discurso floresmagonista (el venido directamente del pensamiento de Flores Magón y el interpretado y adaptado por Raúl Kamffer), es sumamente fácil percibir las similitudes, que representan casi la totalidad de lo aquí presentado. Vemos que uno y otro se amparan en las privaciones básicas para inflamar las ansias de sublevación y la sed de asonada. Empero, lo oportuno es interpretar el par de discrepancias que se asoman y se dejan sentir. Aunque la temporalidad no se especifica, es explicable que la primera cara de Flores Magón no se ponga en evidencia; es decir, se obvia por completo el pensamiento de Ricardo a inicios del siglo XX, mismo que incluso podría parecer reaccionario. La evolución de su filosofía también es pasada por alto, para de lleno presentarnos la versión más extremista del anarquismo floresmagonista.

El otro aspecto que aparece contrapuesto entre ambas perspectivas es el rol de la mujer en los motines y en las huelgas. Mientras que Flores Magón la relega a una función tras bambalinas, apareciendo el hombre como el héroe visible de los desvalidos, en la película, Raúl Kamffer postula que las mujeres floresmagonistas no se limitan a los quehaceres domésticos o a la motivación participativa; la tesis de 'Ora sí: ¡Tenemos que ganar! asume que ellas tuvieron papeles principales en el teatro de la conflagración. En la historia del filme, se convertían en partícipes directos de la contienda y no se limitaban a incitar a los varones para que apretaran con fuerza los rifles, con lo que se construye el ya referido nuevo arquetipo cinematográfico de mujer revolucionaria.

\section{Consideraciones finales}

'Ora sí: ¡Tenemos que ganar! es quizás una de las películas que mejor adaptan la teoría anarquista y de las pocas hechas en México sobre el tema. A decir de anarquistas como Albert Meltzer, el otro caso puntual de una representación cinematográfica del anarquismo mexicano es la producción estadounidense ; Viva Zapata! de Elia Kazan, estrenada en 1952. Sin embargo, como bien señala Richard Porton, el plan original de esta película no era reproducir la política libertaria; fueron las circunstancias propias de la realización (anticomunismo y realce de las tradiciones campesinas) las que sin querer le dieron un carácter anarquista (Porton, 2001: 87- 


\section{Balajú}

88). Otros ejemplos que se relacionen con producciones mexicanas se tienen que buscar fuera del país. El laberinto del fauno (2006), dirigida por Guillermo del Toro, es lo más cercano. En esta cinta se muestra un poco (sin llegar a profundizar) de la resistencia republicana durante la Guerra Civil española. Cabe decir que el plan original era desarrollar la trama durante la Revolución mexicana, pero, por la falta de respaldo financiero, la producción se trasladó a Europa.

Pese a que 'Ora sí: ¡Tenemos que ganar! se grabó y se estrenó fuera del tiempo de los insumos echeverristas, aún gozó de los últimos espaldarazos para la producción fílmica, previo a lo que Eduardo de la Vega llama la época de retroceso. Pese a que -a la llegada de José López Portillo a la presidencia- el Estado perdió su interés por resanar su imagen a través de la defensa de la libre expresión, el primer sexenio de los setenta había dejado huellas profundas en la desinteresada vocación cinematográfica; productoras independientes como la UNAM apoyaron a los cineastas abandonados por el gobierno (De la Vega, 1991: 67-69).

Como ya vimos, respecto del floresmagonismo, las libertades creativas tomadas por Raúl Kamffer resultaron ser mínimas. El cambio más tangible giró en torno al desempeño revolucionario de las mujeres. Una explicación es que la película fue influenciada por el cambio de agenda cultural y social que permitió a las mujeres tener una expansión participativa en la vida política de México. En 1974 se reformaron los artículos 4, 5, 30 y 123 constitucionales para beneficiar la libertad jurídica de género. La democratización en los ámbitos electorales y judiciales impactó sin duda alguna en el cine, por lo que podemos señalar a 'Ora sí: ¡Tenemos que ganar! como una filmación que da fe inequívoca de la modernización y la apertura política.

Desde entonces, y hasta ahora, se han estrenado a nivel mundial un amplio catálogo de películas que abordan al anarquismo. Las hay de corte independiente y con inspiraciones abiertas como Amor y anarquía de Lina Wertmüller (1973), La Patagonia rebelde de Héctor Olivera (1974), Tierra y libertad de Ken Loach (1995), Libertarias de Vicente Aranda, La mujer del anarquista de Peter Sehr y Marie Noëlle (2009) y Anarchists de Yoo Young-Sik (2000). También existen aquellas de gran presupuesto y cobijadas por las grandes productoras hollywoodenses; tal es el caso de Fight Club de David Fincher (1999) y V for Vendetta de James Mc Teigue (2005). Actualmente, las plataformas de servicios digitales entraron al mercado. Un ejemplo es La sombra de la ley de Dani de la Torre (2018), financiada por Netflix.

Por lo anterior, observamos que el campo de análisis histórico del cine es tierra fértil y tiene muchas brechas que pueden explorarse. La pertinencia de hablar de cinematografía 


\section{Balajú}

politizada se encuentra en pleno auge, por lo que trabajos como los de Richard Porton deberían ser inspiración para nuevas investigaciones, incentivando al historiador a revalorizar las metodologías y las herramientas capaces de nutrir su capacidad reflexiva, dando por resultado la diversificación de fuentes y de interpretaciones de los discursos, no solo los escritos, sino también los audiovisuales.

\section{Referencias}

ABAD DE SANTILLÁN, Diego (1978). Ricardo Flores Magón. El Apóstol de la Revolución Social Mexicana. México, D. F.: Centro de Estudios Históricos del Movimiento Obrero Mexicano.

ALVIRA, Pablo (2011). "El cine como fuente para la investigación histórica. Orígenes, actualidad y perspectivas”, Páginas. Revista digital de la Escuela de Historia. Año 3, núm. 4., Rosario: Universidad Nacional de Rosario, 135-152.

AMADOR, Pilar (2002). "El cine desde la mirada del historiador", en Gloria Camarero (ed.), La mirada que habla (cine e ideologías). Madrid: Akal.

CABRERA, Julio (1999). Cine: 100 años de filosofía. Una introducción a la filosofía a través del análisis de películas. Barcelona: Gedisa.

DÍAZ LÓPEZ, Marina (2005). Historia de la producción cinematográfica mexicana, 19761977, Volumen I. Coordinación de Eduardo de la Vega Alfaro. Guadalajara: Universidad de Guadalajara.

ESTRADA ÁLVAREZ, Adriana y Lorena NOYOLA PIÑA (2016). “La mirada militante en el cine independiente del 68 mexicano: evocación, denuncia y propaganda (19681973)”, IMAGOFAGIA. Revista de la Asociación Argentina de Estudios de Cine y Audiovisual. Núm. 14, Argentina: ASAECA, 1-29.

FLORES MAGÓN, Ricardo (1983). Artículos políticos 1910. México, D. F.: Antorcha.

FLORES MAGÓN, Ricardo (1995). El sueño alternativo. Compilación y estudio introductorio de Fernando Zertuche Muñoz. México, D. F.: Fondo de Cultura Económica.

FLORES MAGÓN, Ricardo y Jesús Flores Magón (1967). Batalla a la dictadura. Colección dirigida por Martín Luis Guzmán, México, D. F.: Empresas Editoriales, S. A.

GADAMER, Hans-Georg (2006). Estética y hermenéutica. Introducción de Ángel Gabilondo, traducción de Antonio Gómez Ramos, Madrid: Tecnos. 
GADAMER, Hans-Georg (1999). Poema y diálogo. Traducción de Daniel Najmías y Juan Navarro, Barcelona: Gedisa.

GÓMEZ QUIÑONES, Juan (1977). Las ideas politicas de Ricardo Flores Magón. México, D. F.: Era.

GUTIÉRREZ, Roberto (2000). "La evolución política de México y la formación del estado", El Cotidiano. Vol. 16, núm. 100, marzo-abril de 2000, México, D. F.: UAM-Iztapalapa, 160-167.

KAMFFER, Raúl (1973). "El templo es un bosque de quetzales. Los sacerdotes se apiñan en las gradas”, Revista de la Universidad de México. Vol. XXVIII, núm. 10, México, D. F.: UNAM, 31-39.

KAMFFER, Raúl (1978). [Dir.]'Ora sí: ¡Tenemos que ganar! Producida por la Universidad Nacional Autónoma de México. Duración 90 minutos. Disponible en: https://www.youtube.com/watch?v=PKqwEW5mKqs

KING, John (1994). El carrete mágico. Una historia del cine latinoamericano. Bogotá, Colombia: Tercer Mundo.

LOZANO, Elisa (2018). Toni Kuhn: poeta de la luz. México: Academia Mexicana de Artes y Ciencias Cinematográficas.

MENDOZA GUADARRAMA, Christian (2014). Los setenta: década de contrariedades y del surgimiento del nuevo plantel. México, D. F.: Universidad Autónoma del Estado de México.

MICHEL, Guillermo (1998). Para leer los medios. Prensa, radio, cine y televisión. México, D. F.: Trillas.

PASCUAL GUTIÉRREZ, Iris (2016). "La reformulación del autoritarismo mexicano durante la presidencia de Luis Echeverría (1970-1976). La política cinematográfica como ejemplo", Millars. Espai i Història. Vol. XLI 2016/2, España: Universitat Jaume I, 1543.

PORTON, Richard (2001). Cine y anarquismo. La utopía anarquista en imágenes. Barcelona: Gedisa.

RAMÍREZ MIRANDA, Javier (2015). “Cortometraje documental mexicano, años sesenta: las vías de la politización”, IMAGOFAGIA. Revista de la Asociación Argentina de Estudios de Cine y Audiovisual. Núm. 12, Argentina: ASAECA, 1-28. 
ROSENSTONE, Robert A. (2005). "La historia en imágenes/ la historia en palabras: reflexiones sobre la posibilidad real de llevar la historia a la pantalla", Revista Istor. Núm. 20, México: CIDE, 91-108.

SAMANIEGO, Marco Antonio (2015). ““... El magonismo no existe': Ricardo Flores Magón”, Estudios de Historia Moderna y Contemporánea de México. Núm. 49, enero/junio, México: UNAM, 33-53.

SORLIN, Pierre (1985). Sociología del cine. La apertura para la historia del mañana. México, D. F.: Fondo de Cultura Económica.

VEGA ALFARO, Eduardo de la (1991). "La industria cinematográfica mexicana. Perfil histórico-social”, Cuadernos de divulgación. Segunda época, núm. 37, Guadalajara: Universidad de Guadalajara, 4-85. 